\title{
Dificuldades maternas relatadas acerca da amamentação de recém nascidos prematuros: revisão integrativa
}

RESUMO | Objetivo: Identificar as dificuldades relatadas pelas mães na realização do aleitamento materno do recém-nascido prematuro, internado ou não. Metodologia: Trata-se de uma revisão integrativa de literatura. A busca dos artigos ocorreu em agosto de 2018 na Biblioteca Virtual em Saúde. Foram utilizados os seguintes descritores: "aleitamento materno" e "prematuro". Foram selecionados 13 artigos publicados entre 2008 e 2018. Resultados e Discussão: Após a leitura dos resumos que atendiam aos critérios de inclusão e eram pertinentes às questões norteadoras e objetivo do estudo, verificou-se que entre as dificuldades relatadas estavam: medo, insegurança, desconforto, falta de apoio, dificuldades de pega e de ordenha, entre outras. Conclusão: A análise dos estudos selecionados fortalece a importância da orientação em saúde em todos os cenários, uma vez que a maior parte das queixas e inseguranças seriam sanadas pela orientação.

Palavras-chaves: Recém-nascido; Prematuro; Aleitamento Materno.

\begin{abstract}
Objective: Identify the difficulties reported by mothers in performing breastfeeding of premature newborns, hospitalized or not. Methodology: This is an integrative literature review. The search for articles took place on August 2018 in the Virtual Health Library. The following descriptors were used: "breastfeeding" and "premature". Thirteen articles published between 2008 and 2018 were selected. Results and Discussion: After reading the abstracts that met the inclusion criteria and were pertinent to the guiding questions and objective of the study, it was found that among the reported difficulties were: fear, insecurity, discomfort, lack of support, difficulties in picking and milking, among others. Conclusion: The analysis of the selected studies strengthens the importance of health guidance in all scenarios, since most complaints and insecurities would be addressed by guidance
\end{abstract}

Keywords:Newborn; Premature; Breastfeeding.

RESUMEN | Objetivo: Identificar las dificultades reportadas por las madres para amamantar a los recién nacidos prematuros, hospitalizados o no. Metodología: Esta es una revisión de literatura integradora. La búsqueda de artículos tuvo lugar en agosto de 2018 en la Biblioteca Virtual en Salud. Se utilizaron los siguientes descriptores: "Iactancia materna" y "prematuro". Se seleccionaron 13 artículos publicados entre 2008 y 2018. Resultados y discusión: Después de leer los resúmenes que cumplían con los criterios de inclusión y eran pertinentes a las preguntas orientadoras y al objetivo del estudio, se encontró que entre las dificultades informadas se encontraban: miedo, inseguridad, molestias, falta de apoyo, dificultades para recoger y ordeñar, entre otros. Conclusión: El análisis de los estudios seleccionados refuerza la importancia de la orientación sanitaria en todos los escenarios, ya que la mayoría de las quejas e inseguridades se abordarían mediante orientación.

Descriptores:Recién Nacido; Prematuro; Lactancia Materna.

\section{Bárbara Taís Perissé}

Especialista em Enfermagem do Trabalho pela Universidade Federal do Rio de Janeiro (2013), Especialista em Enfermagem Neonatal pela Universidade Veiga de Almeida (2018). Atualmente é Enfermeira Socorrista do Corpo de Bombeiros do Estado do Rio de Janeiro/CBMERJ.

\section{Elzeni dos Santos Braga}

Mestre pela EEAN/UFRJ. Especialista em Gestão Hospitalar pelo HSL/FIOCRUZ. Especialista em pediatria pela EEAN/UFRJ. Especialista em cardiologia pela EEAP/ UNIRIO/INC/MS nos moldes de residência. Atualmente é Enfermeira Gestora da UTIN Cirúrgica da Fundação Oswaldo Cruz / IFF.

Recebido em: 12/04/2019

Aprovado em: 18/04/2019

\section{Luísa Perissé}

Especialista em Enfermagem do Trabalho pela Universidade Federal do Rio de Janeiro (2013), Especialista em Clínica Médica e Cirúrgica nos Moldes de Residência pela Universidade Federal do Estado do Rio de Janeiro (2015), Especialista em Neonatologia pela Universidade Veiga de Almeida (2018).

\section{Cristiano Bertolossi Marta}

Mestrado em Enfermagem. Doutorado em Enfermagem. Pós-doutorado pela Escola de Enfermagem Aurora Afonso Costa da Universidade Federal Fluminense (EEAAC/ UFF). Professor Adjunto e coordenador da subárea de Administração em Enfermagem do Departamento deFundamentos de Enfermagem da Faculdade de Enfermagem da Universidade do Estado do Rio de Janeiro (DFEN/FENF/NERJ). Coordenador do Núcleo de Pós-Graduação em Enfermagem e Diretor do Núcleo de Pesquisa da Universidade Veiga de Almeida.
INTRODUÇÃO

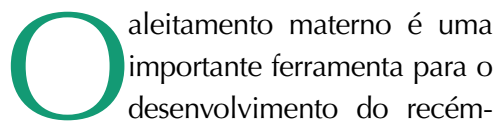
-nascido. Contendo todos os nutrientes necessários para seu crescimento e desenvolvimento, o leite materno contém, ainda, anticorpos, não possui custo, está relacionado com maior sobrevida dos lactentes, menor índice de morbidades e, entre outros motivos, é recomendado pela Organização Mundial da Saúde (OMS) que seja a preferência para a alimentação de recém-nascidos (RN) até os seis meses de vida ${ }^{(1-3)}$.

$\mathrm{O}$ aleitamento materno evita mortes infantis, diarreia, infecção respiratória; diminui o risco de alergias, o risco de hipertensão, colesterol alto e diabetes; reduz a chance de obesidade e proporciona a melhor nutrição. O leite materno é capaz de suprir sozinho 
Perissé, B.T.; Braga, E.S.; Perissé, L.; Marta, C.B.; Dificuldades maternas relatadas acerca da amamentaçăo de recém-nascidos prematuros: revisāo integrativa

as necessidades nutricionais da criança nos primeiros seis meses e continua sendo uma importante fonte de nutrientes no segundo ano de vida, especialmente de proteínas, gorduras e vitaminas ${ }^{(2,3)}$.

Os RN que nasceram prematuros podem se beneficiar ainda mais do aleitamento, pois o leite materno se ajusta ao $\mathrm{RN}$ e à sua idade gestacional, ideal para o sistema digestivo, possivelmente ainda imaturo, nutrindo-o melhor e evitando transtornos e doenças, como intolerâncias ou mesmo Enterocolites, visto que este leite possui maior quantidade de nutrientes do que o leite produzido pelas mães de RN a termo, além de maiores propriedades antinfecciosas ${ }^{(4)}$.

No entanto, embora os benefícios do aleitamento materno sejam inquestionáveis devidos aos inúmeros estudos já existentes sobre suas propriedades e implicações, ainda não se atingiu no Brasil $\mathrm{o}$ índice recomendado e esperado ${ }^{(4,5)}$.

Grande parte dos profissionais de saúde se declara a favor do aleitamento materno, mas, apesar disso, muitas lactantes demonstram insatisfação com relação ao apoio e orientações provenientes daqueles. Um dos motivos que pode levar a esta incongruência é a diferença das percepções acerca deste apoio, do tipo de apoio que a mulher deseja e necessita e o que é entendido pelos profissionais como sendo importante para serem dados ${ }^{(6)}$.

Este estudo é relevante, porque os seus resultados propiciarão o melhor entendimento dos fatores que atrapalham ou impedem que esta ferramenta seja posta em prática. Estes dados, uma vez conhecidos podem melhorar o direcionamento do en-
Quadro 1. Correlação dos descritores "aleitamento materno" e "prematuro". Rio de Janeiro, RJ, Brasil, 2018

\begin{tabular}{lc|}
\hline Resultados & 608 \\
\hline Artigos em português & 232 \\
\hline Disponíveis integralmente & 162 \\
\hline Publicados e ou indexados entre 2008 e 2018 & 126 \\
\hline Estudos incluidos após breve leitura dos resumos e títulos & 30 \\
\hline Estudos incluídos após a leitura integral do artigo & 13
\end{tabular}

Fluxograma 1. Busca e seleção dos estudos. Rio de Janeiro, RJ, Brasil, 2018

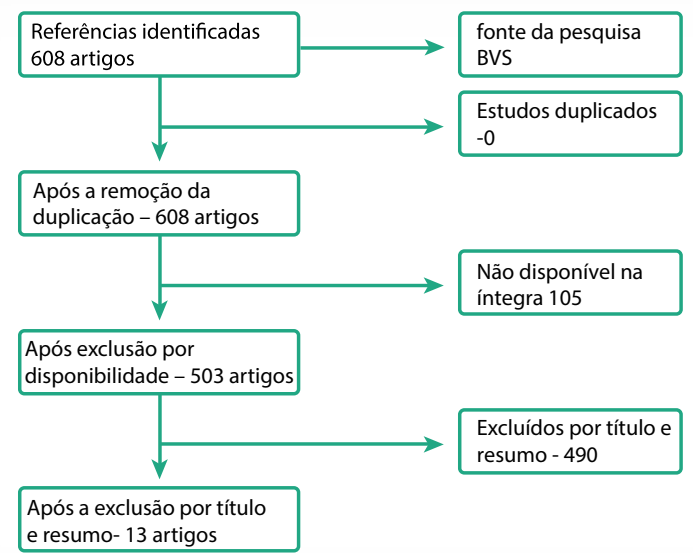

sino e, consequentemente, da assistência de saúde ao binômio mãe-RN, incitando novas pesquisas a este respeito ${ }^{(6)}$.

Objetivou-se identificar as dificuldades relatadas pelas mães na realização do aleitamento materno do RN prematuro, internado ou não.

\section{METODOLOGIA}

Trata-se de um estudo de revisão integrativa, que é a mais ampla abordagem metodológica referente às revisões, permitindo a inclusão de estudos experimentais e não experimentais ${ }^{(7)}$.

Foi delineado por intermédio da PICO que permite que o profissional, da área clínica e de pesquisa, ao ter uma dúvida ou questionamento, localize, de modo acurado e rápido, a melhor informação científica disponível ${ }^{(8)}$.

Para a seleção dos artigos na literatura, foi utilizada uma busca no Portal Biblioteca Virtual em Saúde (BVS), e Bases LILACS, BDENF, Index e Medline, utilizando os seguintes descritores em português e suas combinações: "prematuro" e "aleitamento materno". Foram selecionados artigos publicados entre os anos de 2008 a 2018.

Estabeleceram-se os seguintes critérios de inclusão: estudos em língua portuguesa, dos tipos revisões sistemáticas, pesquisas de campo, relato de experiência, ensaios clínicos e estudos epidemiológicos e artigos disponibilizados integralmente nas bases de dados. Os critérios de exclusão foram: estudos que abordassem o aleitamento materno em $\mathrm{RN}$ a termo ou fora do período neonatal e resumos. A pesquisa foi realizada no mês de setembro de 2018.

Definidos os critérios de inclusão/exclusão do estudo, passou-se para busca e seleção dos artigos: foram encontrados 608 artigos. Após a leitura dos resumos, foram selecionados 13 que atendiam aos critérios e ao objetivo deste estudo. Passou-se então a leitura exaustiva e analítica dos artigos selecionados, que foram categorizados de acordo com o sistema GRADE para a elaboração de evidências. 
Foram selecionados 13 artigos que retratam as dificuldades relatadas pelas mães para o estabelecimento do aleitamento materno.

\section{Quadro 2. Caracterização dos estudos segundo título, autores, ano, país, objetivo, metodologia, resultado, conclusão e nível de}

evidência. Rio de Janeiro, RJ, Brasil, 2018

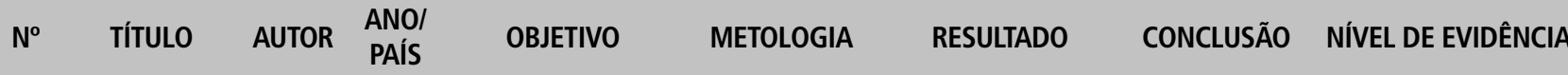

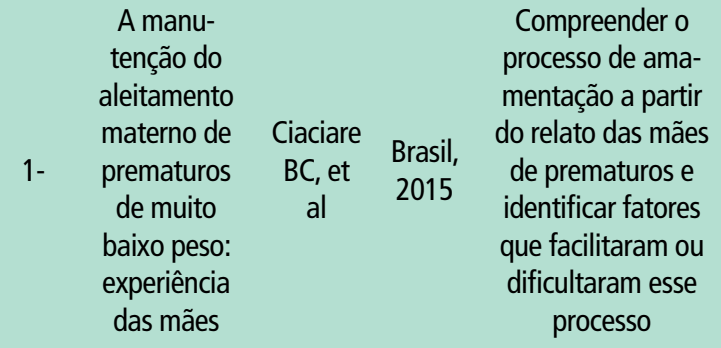

Conclui-se que no contexto da prematuridade, 0 apoio familiar e profissional, o manejo adequado e 0 acolhimento do serviço de maneira individualizada foram reconhecidos como grandes responsáveis pelo sucesso da amamentação, podendo até mesmo sobrepor o desejo materno prévio.
Amamentação de pre-

2- maturos em uma Unidade Neonatal
Identificar as dificuldades maternas em amamentar/aleitar seu filho prematuro em uma Unidade Neonatal (UN), tomar conhecimento de se essa mãe

GorguIho FR Brasil, se sente estimulada et al 2008 a amamentar seu

filho prematuro

nesse ambiente $\mathrm{e}$

descrever como

essa mãe está

vivenciando a

amamentação de

seu filho prematuro

em uma UTI
As mães, ao se defrontarem com a vivência da hospitalização de seu filho, e posteriormente com a impossibilidade de amamentá-lo Grau III tativo

logo após o nascimento, mostram-se ansiosas e com algumas dificuldades nessa nova realidade. 


\begin{tabular}{|c|c|c|c|c|c|c|c|c|}
\hline 3- & $\begin{array}{c}\text { Amamen- } \\
\text { tação em } \\
\text { prematu- } \\
\text { ros: conhe- } \\
\text { cimentos, } \\
\text { sentimen- } \\
\text { tos e viven- } \\
\text { cias das } \\
\text { mães }\end{array}$ & $\begin{array}{l}\text { Cruz, } \\
\text { Ma- } \\
\text { riana } \\
\text { Rama- } \\
\text { lho, et } \\
\text { al }\end{array}$ & $\begin{array}{l}\text { Brasil, } \\
2015\end{array}$ & $\begin{array}{l}\text { Analisar conhecimen- } \\
\text { tos, sentimentos e vi- } \\
\text { vências de mães de RN } \\
\text { prematuros em relação } \\
\text { à amamentação }\end{array}$ & $\begin{array}{l}\text { Trata-se } \\
\text { de um } \\
\text { estudo } \\
\text { transver- } \\
\text { sal, de } \\
\text { caráter } \\
\text { qualita- } \\
\text { tivo. }\end{array}$ & $\begin{array}{l}\text { Os relatos expressaram os } \\
\text { benefícios desta prática, } \\
\text { limitando-se aos benefícios } \\
\text { a saúde do lactente. Os } \\
\text { sentimentos considerados } \\
\text { "positivos" ocorreram com } \\
\text { maior frequência. No que } \\
\text { diz respeito às vivências da } \\
\text { amamentação na UTI neonatal, } \\
\text { os resultados explicitaram ex- } \\
\text { pectativas positivas em relação } \\
\text { ao cumprimento da materni- } \\
\text { dade, embora alguns relatos } \\
\text { indicaram sentimentos de } \\
\text { angústia, medo e dificuldades. } \\
\text { Os relatos indicaram ainda que } \\
\text { a amamentação no lar ocorreu } \\
\text { com maior tranquilidade, no } \\
\text { entanto, observou-se grande } \\
\text { preocupação com o ganho de } \\
\text { peso }\end{array}$ & $\begin{array}{l}\text { Embora as mães } \\
\text { de prematuros } \\
\text { expressem desejo } \\
\text { de amamentar, } \\
\text { este processo é } \\
\text { permeado por } \\
\text { dificuldades que } \\
\text { ocorrem tanto no } \\
\text { processo de tra- } \\
\text { balho na unidade } \\
\text { hospitalar quanto } \\
\text { na vivência } \\
\text { materna após seu } \\
\text { retorno para o lar. }\end{array}$ & Grau III \\
\hline
\end{tabular}

Amamentação exclusiva de recém-nascidos prematuros: percepções e 4- experiências de lactantes usuárias de um serviço público especializado
Investigar percepções e vivências das mães de recém-nascidos $\begin{array}{cc}\text { D.F. } & \text { Brasil, } \\ \text { BRAGA } & 2008 \\ \text { et al. } & \end{array}$ prematuros que amamentaram exclusivamente do $4^{\circ}$ ao $6^{\circ}$ mês de vida.
Estudo seccional exploratório, fundamentado no método qualitativo
Cada mulher vivencia a amamentação a seu modo, a decisão de amamentar está associada ao reconhecimento dos benefícios do leite materno, no entanto o suporte oferecido pela instituição torna decisivo o sucesso da amamentação.
Amamentar exclusivamente um prematuro ainda é um desafio, mas possível. Desde que haja determinação e apoio.
Embora as mães tenham a percepção de que a orientação recebida foi satisfatória, do ponto de vista técnico, foi observado que é necessário utilizar uma orientação dialógica baseada nos aspectos socioculturais da mulher e da família 
Fatores

associados

ao alei-

tamento

materno

6-

exclusivo

em prema-

turos no

primeiro

mês após

a alta

hospitalar
Verificar quais

variáveis maternas e neonatais estariam

Azeve- Brasil, do M, 2013 associadas ao início do aleitamento materno exclusivo (AME) após a alta hospitalar dos recém-nascidos pré-termo (RNPT).
A média de peso dos RN ao nascer foi de $2130 \pm 567,7 \mathrm{~g} \mathrm{e}$ a idade gestacional, de 34,5 \pm 1,4 semanas. 0 início do AME

Estudo em prematuros foi associado à de coorte orientação recebida pela mãe prospec- de amamentar exclusivamente tivo o RN em casa ( $\mathrm{HR}=5,27$; IC $95 \%: 2,26-12,3)$ e de não usar chupeta antes de começar o AME (HR=3,12; IC 95\%: $1,60-6,07$
0 estudo eviden-

cia a necessidade

de orientação às

mães de RNPT

quanto ao

AME, durante a

internação e após

a alta. Ressalta a

importância da

integração entre os serviços de saúde que prestam atendimento no pré-natal e os que realizam seguimento ambulatorial do prematuro, com vistas à melhoria dos índices de amamentação exclusiva nessa população.

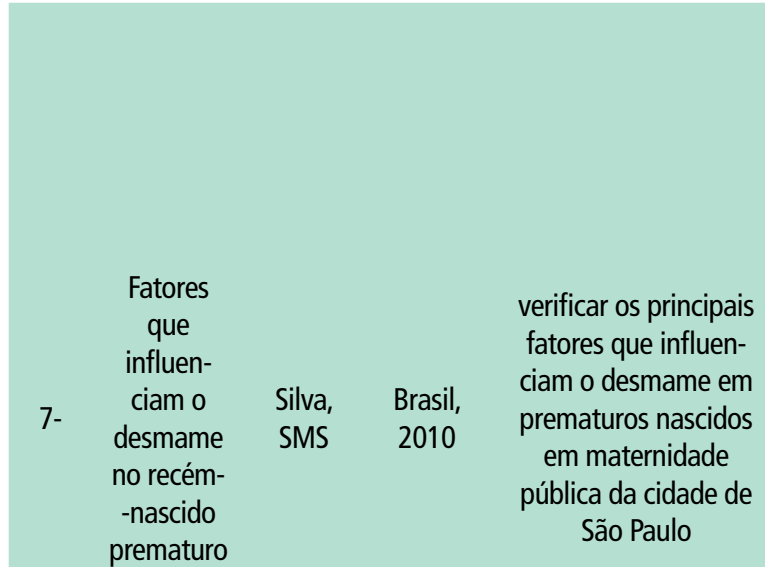

a média de idade para 0 desmame parcial foi de 1,41 meses. Mães que realizaram ordenha durante a internação, ou que iniciaram ou retornaram ao trabalho, introduziram mamadeira mais tardiamente.

Quanto menor o peso ao nascer e a idade gestacional, mais tardia a introdução da mamadeira. Quanto menor a idade de introdução da chupeta, mais precoce o desmame parcial. A média de idade para o desmame total foi de 2,93 meses. Mães que internaram na enfermaria canguru, ou que iniciaram ou voltaram ao trabalho, interromperam 0 aleitamento materno mais tardiamente. os achados do presente trabalho apontam para a importância de fatores controláveis pela equipe de saúde na prevenção do desmame precoce em prematuros, como ordenha, metodologia canguru e orientação para o não uso de chupetas. Fatores não controláveis como peso ao

Grau III cional

Manutenção da Lactação: um desa-

8- fio para mães de DO M, Brasil, et al 2008 prematuros hospitalizados
Identificar a percepção da mãe acerca da manutenção da lactação durante a internação do filho prematuro
Estudo

de caso

coletivo,

qualitativo nascer e trabalho materno, mostraram-se indicativos de maior permanência do aleitamento

materno. 


\begin{tabular}{|c|c|c|c|c|c|c|c|c|}
\hline 9- & $\begin{array}{l}\text { Percepção } \\
\text { das mães } \\
\text { de recém- } \\
\text {-nascidos } \\
\text { prematu- } \\
\text { ros hospi- } \\
\text { talizados } \\
\text { acerca da } \\
\text { amamen- } \\
\text { tação }\end{array}$ & $\begin{array}{l}\text { Bezerra, } \\
\text { Marce- } \\
\text { la Jucá; } \\
\text { et al }\end{array}$ & $\begin{array}{l}\text { Brasil, } \\
2017\end{array}$ & $\begin{array}{l}\text { compreender como } \\
\text { as mães percebem o } \\
\text { processo de amamen- } \\
\text { tação de seu filho pre- } \\
\text { maturo hospitalizado } \\
\text { na Unidade de Terapia } \\
\text { Intensiva Neonatal }\end{array}$ & $\begin{array}{l}\text { estudo } \\
\text { descriti- } \\
\text { vo-explo- } \\
\text { ratório de } \\
\text { abor- } \\
\text { dagem } \\
\text { qualitativa }\end{array}$ & $\begin{array}{l}\text { Evidenciou-se a percepção da } \\
\text { amamentação como impor- } \\
\text { tante para a criança no que } \\
\text { diz respeito ao crescimento, de- } \\
\text { senvolvimento e recuperação } \\
\text { hospitalar. }\end{array}$ & $\begin{array}{l}\text { A manutenção } \\
\text { da lactação é um } \\
\text { processo com- } \\
\text { plexo que deve } \\
\text { ser aprendido } \\
\text { pelas mães de } \\
\text { prematuros A } \\
\text { amamentação ao } \\
\text { seio foi percebida } \\
\text { pelas mães de } \\
\text { prematuros hos- } \\
\text { pitalizados como } \\
\text { uma conquista } \\
\text { alcançada pelos } \\
\text { esforços conjuntos } \\
\text { do binômio } \\
\text { mãe-filho. }\end{array}$ & Grau III \\
\hline $10-$ & $\begin{array}{l}\text { Percepção } \\
\text { de mães } \\
\text { sobre o } \\
\text { processo } \\
\text { de ama- } \\
\text { mentação } \\
\text { de recém- } \\
\text {-nascidos } \\
\text { prema- } \\
\text { turos na } \\
\text { unidade } \\
\text { neonatal }\end{array}$ & $\begin{array}{l}\text { Aman- } \\
\text { do AR, } \\
\text { et al }\end{array}$ & $\begin{array}{l}\text { Brasil, } \\
2016\end{array}$ & $\begin{array}{l}\text { Analisar a percepção } \\
\text { das mães quanto } \\
\text { ao processo de } \\
\text { amamentação de } \\
\text { recém-nascidos pré- } \\
\text {-termo internados em } \\
\text { Unidade Neonatal de } \\
\text { Cuidados Intermediá- } \\
\text { rios e Intensivo }\end{array}$ & $\begin{array}{l}\text { Estudo } \\
\text { descritivo } \\
\text { de abor- } \\
\text { dagem } \\
\text { qualitativa }\end{array}$ & $\begin{array}{l}\text { As mães reconheceram a } \\
\text { importância da prática da ama- } \\
\text { mentação para os filhos, porém } \\
\text { encontraram dificuldades de } \\
\text { amamentar os filhos prematu- } \\
\text { ros sob hospitalização, devido } \\
\text { ao estado crítico e às rotinas } \\
\text { dos setores de internamento }\end{array}$ & $\begin{array}{l}\text { O aleitamento } \\
\text { de recém-nas- } \\
\text { cido pré-termo } \\
\text { hospitalizado } \\
\text { exige atenção } \\
\text { especial das mães } \\
\text { e principalmente } \\
\text { dos profissionais } \\
\text { de saúde, que } \\
\text { constituem ferra- } \\
\text { menta essencial } \\
\text { para facilitar o } \\
\text { contato entre } \\
\text { mãe-filho durante } \\
\text { esse período, favo- } \\
\text { recendo a prática } \\
\text { da amamentação } \\
\text { e a consequente } \\
\text { redução do des- } \\
\text { mame precoce. }\end{array}$ & Grau III \\
\hline $11-$ & $\begin{array}{l}\text { Percepção } \\
\text { materna } \\
\text { do aleita- } \\
\text { mento no } \\
\text { contexto } \\
\text { da prema- } \\
\text { turidade }\end{array}$ & $\begin{array}{c}\text { Braga } \\
\text { PP, et al }\end{array}$ & $\begin{array}{l}\text { Brasil, } \\
2012\end{array}$ & $\begin{array}{c}\text { evidenciar a percepção } \\
\text { materna acerca do } \\
\text { aleitamento materno } \\
\text { do prematuro }\end{array}$ & $\begin{array}{l}\text { Estudo } \\
\text { descri- } \\
\text { tivo de } \\
\text { natureza } \\
\text { qualitativa }\end{array}$ & $\begin{array}{l}\text { Existe o reconhecimento da } \\
\text { importância do aleitamento } \\
\text { materno, entretanto o contexto } \\
\text { da prematuridade gera difi- } \\
\text { culdades para a manutenção } \\
\text { do mesmo devido à condição } \\
\text { fisiopatológica do recém-nasci- } \\
\text { do pré-termo ou das condições } \\
\text { emocionais da mãe. }\end{array}$ & $\begin{array}{l}\text { Há um empenho } \\
\text { em manter a } \\
\text { prática da ama- } \\
\text { mentação, pois } \\
\text { as informantes } \\
\text { reconhecem os } \\
\text { benefícios do leite } \\
\text { materno para o } \\
\text { recém-nascido } \\
\text { prematuro. }\end{array}$ & Grau III \\
\hline
\end{tabular}




\begin{tabular}{|c|c|c|c|c|c|c|c|c|}
\hline $12-$ & $\begin{array}{c}\text { Práticas } \\
\text { favorece- } \\
\text { doras do } \\
\text { aleita- } \\
\text { mento } \\
\text { materno } \\
\text { ao recém- } \\
\text {-nascido } \\
\text { prematuro } \\
\text { interna- } \\
\text { do na } \\
\text { unidade } \\
\text { de terapia } \\
\text { intensiva } \\
\text { neonatal }\end{array}$ & $\begin{array}{c}\text { Santos } \\
\text { TAS, } \\
\text { et al }\end{array}$ & $\begin{array}{l}\text { Brasil, } \\
2012\end{array}$ & $\begin{array}{c}\text { conhecer as práticas } \\
\text { favorecedoras do alei- } \\
\text { tamento materno na } \\
\text { assistência ao recém- } \\
\text {-nascido prematuro } \\
\text { internado na Unidade } \\
\text { de Terapia Intensiva } \\
\text { Neonatal }\end{array}$ & $\begin{array}{c}\text { Revisão } \\
\text { integrati- } \\
\text { va da } \\
\text { literatura }\end{array}$ & & $\begin{array}{l}\text { Práticas como o } \\
\text { método mãe can- } \\
\text { guru, a ordenha } \\
\text { mamária, as técni- } \\
\text { cas de relaxamen- } \\
\text { to, a acupuntura } \\
\text { e a utilização de } \\
\text { galactogogos } \\
\text { têm um impacto } \\
\text { positivo sobre a } \\
\text { amamentação de } \\
\text { recém-nascidos } \\
\text { prematuros }\end{array}$ & Grau III \\
\hline
\end{tabular}

Após a leitura dos estudos selecionados por associação com o tema, rea- lizou-se a coleta das informações buscadas nos mesmos, as quais foram abaixo relacionadas de acordo com o estudo de onde foram encontradas.

\section{Quadro 3. Dificuldades relatadas pelas mães no aleitamento do prematuro. Rio de Janeiro, RJ, Brasil, 2018}

\section{Título do Estudo}

A manutenção do aleitamento materno de prematuros de muito baixo peso: experiência das mães

Amamentação de prematuros em uma Unidade Neonatal

Amamentação em prematuros: conhecimentos, sentimentos e vivências das mães

Amamentação exclusiva de recém-nascidos prematuros: percepções e experiências de lactantes usuárias de um serviço público especializado

\section{Dificuldades relatadas}

Leite insuficiente, insegurança relacionada à prematuridade, dificuldade na pega, pressão de sucção ineficaz, necessidade de voltar a trabalhar, dificuldade na ordenha

Ansiedade, dor na ordenha manual, percepção de baixa produção de leite, exaustão, ambiente hospitalar, exaustão causada pelas idas e vindas

Medo de tocar no RN frágil, insuficiência de leite, horários e rotinas estabelecidos pela UTI, medo de não ganhar o peso necessário

Dificuldade na pega, no posicionamento do RN, pressão social para a introdução de mamadeira, falta de apoio familiar, exaustão da posição exigida pelo método canguru e consequente sono não reparador

Aprendizado e prática do aleitamento na unidade de terapia intensiva neonatal: vivência de mulheres

Mama cheia, dificuldade de pega, medo e dor na ordenha.

Fatores associados ao aleitamento materno exclusivo em prematuros no primeiro mês após a alta hospitalar

Insaciedade do RN

Fatores que influenciam o desmame no recém-nascido prematuro
Dificuldade com a ordenha, pouca produção de leite, retorno materno ao trabalho 
Manutenção da Lactação: um desafio para mães de prematuros hospitalizados.
Constrangimento na exposição das mamas, medo dos equipamentos do banco de leite, dor no uso dos equipamentos do banco de leite, queixa de excesso de informação
Percepção das mães de recém-nascidos prematuros hospitalizados acerca da amamentação

Percepção de mães sobre o processo de amamentação de recém-nascidos prematuros na unidade neonatal

Percepção materna do aleitamento no contexto da prematuridade

Práticas favorecedoras do aleitamento materno ao recém-nascido prematuro internado na unidade de terapia intensiva neonatal

Prematuro: experiência materna durante amamentação em unidade de terapia intensiva neonatal e pós-alta
Medo de contato físico com o lactente frágil, pega ineficaz

Internação do neonato na UTI, falta de privacidade para a ordenha na UTI, medo de contato físico devido a fragilidade

Sucção ineficaz, pouca produção de leite

Dor na Ordenha, ansiedade relacionada à hospitalização, baixa produção de leite

Falta de orientação dos profissionais de saúde no período noturno, insaciedade do RN, exaustão, retorno materno ao trabalho
Após a coleta dos dados, verificou-se a similaridade das dificuldades encon- tradas em diversos relatos de modo que, com fins didáticos, estes foram classifica- dos e reagrupados por categorias, abaixo relacionadas:

\section{Quadro 4. Categorização dos relatos. Rio de Janeiro, RJ, Brasil, 2018}

Fatores psicossociais

Ansiedade relacionada à hospitalização do $\mathrm{RN}$, medo de contato físico com o frágil neonato, constrangimento na exposição das mamas, medo dos equipamentos do banco de leite, medo da ordenha, medo do RN não ganhar peso.

Retorno materno ao trabalho, pressão para uso de mamadeira, falta de apoio familiar

Fatores relacionados ao RN

Fatores relacionados à mãe

Fatores relacionados às instituições e aos profissionais de saúde

Fatores associados ao aleitamento materno exclusivo em prematuros no primeiro mês após a alta hospitalar

Fatores que influenciam o desmame no recém-nascido prematuro
Ansiedade, dor na ordenha manual, percepção de baixa produção de leite, exaustão, ambiente hospitalar, exaustão causada pelas idas e vindas

Insaciedade do RN, sucção ineficaz, internação do neonato em UTI, dificuldade de pega, incapacidade de manter pressão de sucção apropriada

Dor na ordenha, baixa produção de leite, dor na mama cheia, dificuldade no posicionamento do RN, falta de qualidade de sono, exaustão

Horários e rotinas estabelecidos pela UTI, exaustão causada pelas idas e vindas à unidade, exaustão causada pela posição necessária na manutenção da realização do método canguru, Falta de orientação dos profissionais de saúde no período noturno, falta de privacidade para a ordenha na UTI, queixa de excesso de informação em curto período
Dificuldade com a ordenha, pouca produção de leite, retorno materno ao trabalho

\section{DISCUSSÃo}

A puérpera e seu $\mathrm{RN}$, em circunstâncias normais, formam um binômio mãe-filho, no entanto, na situação de prematuridade em que o $\mathrm{RN}$ precisa de internação em UTI este binômio é quebrado e, enquanto o lactente permanece internado recebendo os cuidados intensivos que lhe garantirão o amadurecimento de seus sistemas para a adaptação a vida, a lactante recebe alta. Esta separação do binômio repercute nos dois envolvidos em vários aspectos e fatores, principalmente no que tange ao processo de lactação, neste estudo foi possível buscar os aspectos percebidos e relatados pelas lactantes como dificultantes deste processo abaixo relacionados por categorias.

\section{Fatores Psicossociais}

Entre os fatores categorizados por este estudo como psicológicos, o mais relatado foi o medo, aparecendo diversas vezes e relacionados a diversos fatores. A situação de prematuridade em si já é um fator que pode desencadear esse tipo de sentimento e, portanto, se projetar para todos as outras questões ${ }^{(9)}$. Ansiedade e constrangimento também foram relacionados, é sabido que tais sentimentos desencadeiam liberação de substâncias endógenas, como a adrenalina e dopamina, que diminuem a produção de ocitocina e prolactina e, desta maneira, interferem diretamente na produção do 
leite materno. Faz-se necessário, portanto, apoio psicológico profissional a essas mulheres, assim como orientações, para que elas se ambientem à sua nova condição e possam desenvolver a resiliência necessária a fim de enfrentar a situação sem desânimo ${ }^{(10)}$.

Nos fatores sociais, existe a pressão social por uso de mamadeira e falta de apoio familiar na manutenção do aleitamento materno. Os fatores culturais, tais como as crenças aprendidas e praticadas pela família da lactante, irão interferir diretamente no processo de lactação, uma vez que esta demanda grande dedicação e abnegação (10-12). A lactante precisa, portanto, ter a convicção de que o aleitamento materno é a melhor conduta para o desenvolvimento de seu filho ${ }^{(13)}$. Orientação adequada durante o pré-natal e na instituição hospitalar pode ajudar a desmistificar questões massificadas pela mídia como propagandas de substitutos do leite materno e introdução de farinhas ${ }^{(14)}$. Essas orientações em saúde devem incluir idealmente ao parceiro e aos familiares próximos sempre que possível.

Foi também relacionado à situação de necessidade de retorno ao trabalho por esta mulher. Vive-se em uma sociedade em que a mulher no mercado de trabalho é cada vez mais presente e isso inclui, principalmente, a mulher em idade fértil. Medidas de proteção à lactação e de incentivo ao aleitamento materno, assim como ampliação de licença-maternidade precisam ser tomadas. Além disso, a mulher precisa ser orientada quanto à possibilidade de armazenamento e congelamento do leite materno para tentar prolongar o aleitamento deste lactente prematuro $^{(15,16)}$.

\section{Fatores relacionados ao RN}

Com relação ao $\mathrm{RN}$, foram relatadas situações diretamente relacionadas com a prematuridade, tais como: a dificuldade de pega, sucção ineficaz, internação em UTI e incapacidade de manter a sucção apropriada. Essas condições, muitas vezes, são inerentes à imaturidade do orga- nismo que ainda está se desenvolvendo para aprender a mamar de forma coordenada, com força e constância. É importante salientar à mãe, no entanto, que este é um processo temporário, e que ela precisa manter a estimulação da mama para fornecer o leite que pode ser administrado por hora de forma indireta como copinho e sondas, mas também para o momento em que o RN estiver pronto para sugar e, assim, dar continuidade ao aleitamento $^{(17)}$.

Com relação ao relato da mãe na insaciedade apresentada pelo RN, é preciso observação deste $\mathrm{RN}$ e muita orientação. A situação de prematuridade pode levar a diversos desconfortos e existe uma tendência a associar choros com fome. Orientar a mãe com relação à capacidade gástrica em cada fase de desenvolvimento pode ajudar a diminuir esse sentimento $^{(17,18)}$.

\section{Fatores relacionados à mãe}

Nos fatores categorizados como relacionados à mãe, a dor na mama/ordenha foi relatado quase sempre junto do relato/ queixa/alegação de percepção de baixa produção de leite. Quando o RN estiver internado e não puder realizar a sucção na mama, a fim de manter ativo o processo de produção de leite, deve-se manter a estimulação da mama por intermédio da ordenha, seja ela manual ou com uso de equipamento próprio para este fim. Deve-se também orientá-la quanto à correta realização do procedimento de ordenha, uma vez que a dor pode estar relacionada com a manipulação errada da mama na ordenha. A mãe deve ser orientada ainda quanto às possíveis posições para acomodação do RN de forma a facilitar o processo $^{(10,17)}$.

Fatores relacionados à instituição e aos profissionais de saúde

Dentro dos fatores relacionados, surgem relatos principalmente de fatores estruturais, mas também fatores relacionados às condutas dos profissionais, horários e rotinas estabelecidos pela UTI, exaustão causada pelas idas e vindas à unidade e pela posição necessária na manutenção da realização do método canguru são queixas que poderiam ser resolvidas com a estruturação da unidade para apoiar melhor a lactante ${ }^{(19)}$.

Com relação à falta de orientação dos profissionais de saúde no período noturno e falta de privacidade para a ordenha na UTI, é preciso enfatizar que todos os profissionais que possuem contato com esta mulher são responsáveis pelo sucesso da amamentação. Não deve haver terceirização das orientações, elas devem ser dadas por todos os profissionais em todos os cenários e horários, isso também evitaria a queixa de excesso de informação em curto período, pois seria dada de forma mais fragmentada e ratificada diversas vezes. Desde a atenção básica até o ambiente hospitalar ${ }^{(6,14,19)}$.

\section{CONCLUSÃO}

O processo de aleitamento ainda é considerado, muitas vezes, como uma habilidade instintiva e inerente à toda mulher, no entanto, embora fisiológico, possui muitas peculiaridades e estas aumentam em número e tamanho quando se relacionam com um organismo prematuro, imaturo em seus sistemas, principalmente digestivo e respiratório, que estão ambos diretamente relacionados. O RN prematuro não tem a mesma capacidade de coordenar a respiração com a deglutição, não possui a mesma capacidade digestiva e a mesma força de sucção que um RN a termo sadio. Todos os RN precisam aprender a mamar e todas as mães precisam aprender a lactar e, neste processo de aprendizado e desenvolvimento, é necessária a correta orientação por um profissional de saúde habilitado para tal, além do reforço das orientações por todos os outros profissionais de saúde.

A orientação é capaz de resolver quase a totalidade das demandas apresentadas pelas mulheres nos estudos encontrados, as quais não devem se restringir à mulher apenas, mas à família e à comuni- 
dade de maneira geral. Faz se necessária a realização de novos estudos que busquem a percepção da mulher, as dificuldades relatadas pela mulher. Muitos estudos abordam dificuldades de aleitamento como algo objetivo, mas não levam em consideração os sujeitos envolvidos.

Ainda são tomadas poucas medidas com a finalidade de promover o conforto a esta mulher. Conforto que a uma vista rápida pode parecer supérfluo diante de tantas demandas, mas que pode ser decisivo no sucesso do estabelecimento da amamentação, o que diminuiria o tempo de internação dos prematuros e futuras internações uma vez que é de conhecimento geral a proteção a imunidade proporcionada pelo leite materno. É cruel atribuir o sucesso da amamentação apenas à força de vontade da mulher, é preciso oferecer condições dignas para que ela possa sustentar toda a situação.

O sujeito é subjetivo e precisa ser ouvido em suas demandas, é necessário estudar esse sujeito, a mãe, através de seu olhar para melhor compreendermos as questões envolvidas. Ela faz parte do binômio. Olhar apenas unilateralmente ou observar pode gerar resultados especuladores, como exemplo, um estudo objetivo não teria identificado os medos relatados e nem as considerações acerca das estruturas físicas das instituições ou da falta de empatia e orientações dos profissionais de saúde. Espera-se que o presente estudo possa contribuir para estímulo, para que surjam novos estudos, que mais mulheres sejam ouvidas, que estimule o desenvolvimento de estratégias para orientação e aconselhamento da mulher no estabelecimento do aleitamento materno de $\mathrm{RN}$ prematuros.

\section{Referências}

1. Soares JPO, Novaes LFG, Araújo CMT, Vieira ACC. Amamentação natural de recém-nascidos pré-termo sob a ótica materna: uma revisão integrativa. Rev. CEFAC [Internet]. 2016 Feb [cited 2018 Sep 17]; 18(1):232-241. Available from: http://www.scielo.br/scielo.php?scrip$\mathrm{t}=$ sci_arttext\&pid=S1516-18462016000100232\&lng=en. http://dx.doi. org/10.1590/1982-021620161819215.

2. Ministério da Saúde, Secretaria de Atenção à Saúde, Departamento de Ações Programáticas Estratégicas (BR). Atenção Humanizada ao Recém-Nascido de Baixo Peso: Método Mãe Canguru. $2^{\circ}$ ed. Brasília (DF): MS; 2011. 3. Silva L, Tavares L, Gomes C. Dificuldades na amamentação de lactentes prematuros. Distúrbios da Comunicação [Internet]. 2014 [cited 2018 Sep 17]; 26(1). Available from: http://revistas.pucsp.br/index.php/dic/article/ view/19010/14197.

4. Vannuchi MTO, et al. Iniciativa Hospital Amigo da Criança e aleitamento materno em unidade de neonatologia. Rev. Saúde Pública [Internet]. 2004 Jun [cited 2018 Sep 17]; 38(3):422-428. Available from: http://www.scielo.br/scielo. php?script=sci_arttext\&pid=S0034-89102004000300013\&lng=en\&nrm=iso. 5. Sassá AH, Schmidt KT, Rodrigues BC, Ichisato SMT, Higarashi IH, Marcon SS. RN pré-termo: aleitamento materno e evolução ponderal. Rev. bras. enferm. [Internet]. 2014 Aug [cited 2018 Sep 16]; 67(4):594-600. Available from: http://www.scielo.br/scielo.php?script=sci_arttext\&pi$d=$ S0034-71672014000400594\&lng=en. http://dx.doi.org/10.1590/00347167.2014670415.

6. Ministério da Saúde, Secretaria de Atenção à Saúde, Departamento de Atenção Básica (BR). Saúde da criança: aleitamento materno e alimentação complementar / Ministério da Saúde, Secretaria de Atenção à Saúde, Departamento de Atenção Básica. - 2. ed. - Brasília: Ministério da Saúde, 2015. 184 p.: il. - (Cadernos de Atenção Básica; n. 23).

7. Santos CMC, Pimenta CAM, Nobre MRCuce. A estratégia PICO para a construção da pergunta de pesquisa e busca de evidências. Rev. Latino-Am. Enfermagem [Internet]. 2007 June [cited 2018 Sep 14]; 15(3):508-511. Available from: http://www.scielo.br/scielo.php?script=sci_arttext\&pi$d=S 0104-11692007000300023 \& \operatorname{lng}=e n$.

8. Pereira LB, Abrão ACFV, Ohara CVS, Ribeiro CA. Vivências maternas frente às peculiaridades da prematuridade que dificultam a amamentação. Texto contexto - enferm. [Internet]. 2015 Mar [cited 2018 Sep 16]; 24(1):55-63. Available from: http://www.scielo.br/scielo.php?script=sci_arttext\&pid=S0104-07072015000100055\&lng=en.

9. Ciaciare $B C$, et al. A manutenção do aleitamento materno de prematuros de muito baixo peso: experiência das mães. Revista Eletrônica de Enfermagem [Internet]. 2016 [cited 2018 Sep 16]; 17(3). Available from: https://revistas. ufg.br/fen/article/view/27548.

10. Braga DF, Machado MMT, Bosi MLM. Amamentação exclusiva de recém- -nascidos prematuros: percepções e experiências de lactantes usuárias de um serviço público especializado. Rev. Nutr. [Internet]. 2008 June [cited 2018 Sep 16]; 21(3):293-302. Available from: http://www.scielo.br/scielo.php?script=sci_arttext\&pid=S1415-52732008000300004\&lng=en\&nrm=iso.

11. Silva SMS, Segre CAM. Fatores que influenciam o desmame no recém-nascido prematuro. Rev. Bras. Cresc. e Desenv. Hum. 2010.

12. Alves JS, Oliveira MIC, Rito RVVF. Orientações sobre amamentação na atenção básica de saúde e associação com o aleitamento materno exclusivo. Ciênc. saúde coletiva [Internet]. 2018 Apr [cited 2018 Sep 16]; 23(4):10771088. Available from: http://www.scielo.br/scielo.php?script=sci_arttext\&pi$d=$ S1413-81232018000401077\&lng=en.

13. Brasileiro AA, Ambrosano GMB, Marba STM, Possobon RF. A amamentação entre filhos de mulheres trabalhadoras. Rev. Saúde Pública [Internet]. 2012 Aug [cited 2018 Sep 16]; 46(4):642-648. Available from: http://www.scielo. br/scielo.php?script=sci_arttext\&pid=S0034-89102012000400008\&lng=en. 14. Braga DF, Machado MMT, Bosi MLM. Amamentação exclusiva de recém-nascidos prematuros: percepções e experiências de lactantes usuárias de um serviço público especializado. Rev. Nutr. [Internet]. 2008 June [cited $2018 \mathrm{Sep}$ 16]; 21(3):293-302. Available from: http://www.scielo.br/scielo.php?script=sci_arttext\&pid=S1415-52732008000300004\&lng=en.

15. Monteiro FR, Buccini GS, Venâncio SI, Costa THM. da. Influência da licença-maternidade sobre a amamentação exclusiva. J. Pediatr. [Internet]. 2017 Oct [cited 2018 Se 16]; 93(5): 475-481. Available from: http://www.scielo.br/ scielo.php?script=sci_arttext\&pid=S0021-75572017000500475\&lng=en. 16. Rodrigues A, Elaine LM, Tatiane CT, Stela MMP, Cristiane CP, Tronco CS Manutenção do aleitamento materno de recém-nascidos pré-termo: revisão integrativa da literatura. Revista Eletrônica de Enfermagem [Internet]. 2013 [cited 2018 Sep 16]; 15(1):253-64. DOI: https://doi.org/10.5216/ree. v15i1.17067

17. Marques ES, Cotta RMM, Priore SE. Mitos e crenças sobre o aleitamento materno. Ciênc. saúde coletiva [Internet]. 2011 May [cited 2018 Sep 16]; 16(5):2461-2468. Available from: http://www.scielo.br/scielo.php?script=sci_arttext\&pid=S1413-81232011000500015\&lng=en.

18. Serra SOA, Scochi CGS. Dificuldades maternas no processo de aleitamento materno de prematuros em uma UTI neonatal. Rev. Latino-Am. Enfermagem [Internet]. 2004 Aug [cited 2018 Sep 16]; 12(4):597-605. Available from: http://www.scielo.br/scielo.php?script=sci arttext\&pid=S0104-11692004000400004\&lng=en.

19. Souza MHN, Nespoli A, Zeitoune RCG. Influência da rede social no processo de amamentação: um estudo fenomenológico. Esc. Anna Nery [Internet]. 2016 [cited 2018 Sep 16]; 20(4):e20160107. Available from: http://www.scielo.br/scielo.php?script=sci_arttext\&pi$d=S 1414-81452016000400224 \& \operatorname{lng}=e n$. 